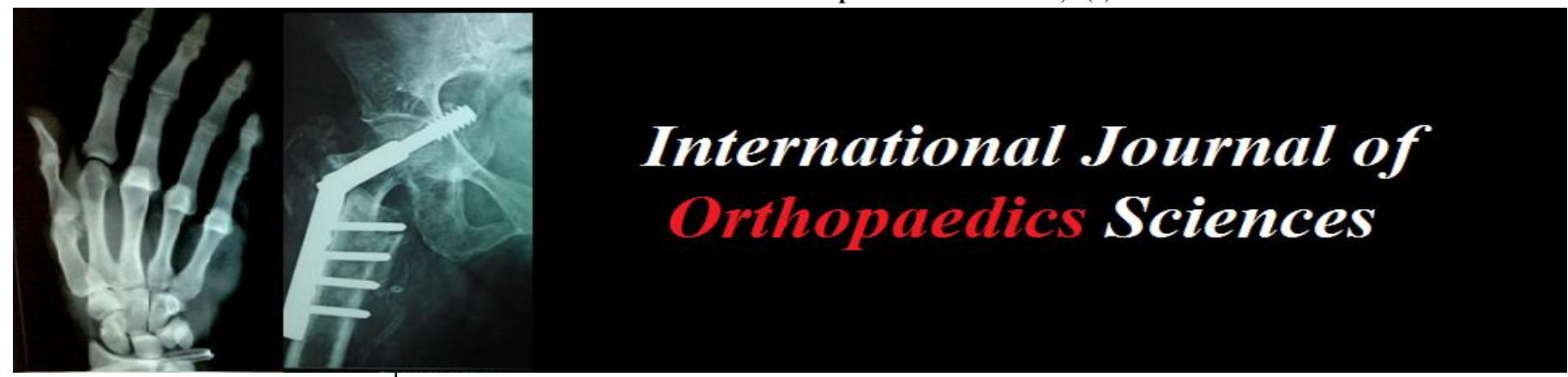

E-ISSN: 2395-1958

P-ISSN: 2706-6630

IJOS 2020; 6(1): 139-142

(C) 2020 IJOS

www.orthopaper.com

Received: 08-11-2019

Accepted: 12-12-2019

Dr. Vamshikrishna Chand

Nimmagadda

Department of Orthopaedics

Vydehi Institute of Medical

Sciences and Research Center,

Bangalore, Karnataka, India

Dr. Hiranya Kumar Seenappa Department of Orthopaedics, Vydehi Institute of Medical

Sciences and Research Center,

Bangalore, Karnataka, India

Dr. Karthik Narayanamurthy Mittemari

Department of Orthopaedics, Vydehi Institute of Medical Sciences and Research Center, Bangalore, Karnataka, India

Corresponding Author: Dr. Karthik Narayanamurthy Mittemari

Department of Orthopaedics, Vydehi Institute of Medical Sciences and Research Center, Bangalore, Karnataka, India

\section{Outcomes of instrumented posterolateral fusion in patients with low grade lumbar spondylolisthesis}

\author{
Dr. Vamshikrishna Chand Nimmagadda, Dr. Hiranya Kumar Seenappa \\ and Dr. Karthik Narayanamurthy Mittemari
}

DOI: $\underline{\text { https://doi.org/10.22271/ortho.2020.v6.i1c.1849 }}$

\section{Abstract}

Background: Spondylolisthesis the forward slippage of a cephalad vertebra on a caudal vertebra. Fusion is the recommended procedure for spondylolisthesis. However, choice between the different methods of fusion remains under debate. Posterolateral fusion with posterior instrumentation (PLF) has shown good clinical outcomes and fusion rates.

Objectives: To study clinical and radiological outcomes of PLF in grade 1 and 2 spondylolisthesis

Methods: This is a prospective study of 30 patients who underwent PLF and followed up for 2 years. The outcome measures were (1) clinical outcomes as assessed with a visual analogue scale and the Modified Oswestry Disability Index, (2) the fusion rate based on radiographs.

Results: There was a significant improvement in VAS of low back pain $(82.45 \%, p<0.001)$ and VAS of radiating $(93.55 \% ; p<0.001)$. The ODI scores were significantly improved $(69.86 \%, p<0.001)$ at 2 years follow up. The fusion rate was $70 \%$ and $63.33 \%$ patients reported excellent outcomes.

Conclusion: Based on 2 year clinical outcomes and the fusion rates of PLF, we conclude that PLF is an excellent surgical procedure for management of low grade spondylolisthesis.

Keywords: PLF, fusion, VAS, ODI, spondylolisthesis

\section{Introduction}

Spondylolisthesis commonly describes the forward slippage of a cephalad vertebra on a caudal vertebra. Although vertebra may slip in any direction, forward slippage is more commonly reported ${ }^{[1]}$. Surgery with fusion has been proven to be the effective management of spondylolisthesis ${ }^{[2]}$. Various methods of fusion have been described. They can broadly be classified as posterolateral fusion and interbody fusion ${ }^{[3]}$.

Posterolateral fusion combined with posterior instrumentation (PLF) is a widely used procedure with proven fusion rates and superior clinical outcomes. PLF includes pedicle screw fixation, decompression of the spinal canal to relieve pain and nerve compression, and fusion with bone graft. PLF has been shown to be safe, with improved biomechanics of the spine by restoring sagittal alignment ${ }^{[4]}$.

In spite of several recent studies, there remains considerable debate for the best operative technique for spondylolisthesis ${ }^{[5-11]}$.

Our objectives were; 1 . To compare functional outcomes as assessed with a visual analogue scale (VAS) and the Oswestry disability index (ODI) before surgery and 2 years after the surgery. 2 . To assess fusion rates at 2 years after the surgery.

\section{Material and Methods}

Source of Data: The study was conducted in the Department of Orthopaedics, Vydehi Institute of Medical Sciences and Research Centre, Whitefield, Bangalore, following institutional guidelines and after ethical committee approval

Patient Demographics: The study was a prospective study of 30 patients conducted between January 2016 and May 2019, with a follow up of 2 years. We included patients between ages 18-70 years, with single level low grade spondylolisthesis (Meyerding grade I or II) and failed conservative therapy. Patients with, failed back syndrome, infections, bedridden/non ambulatory patients and cognitively impaired patients were excluded from the study. 
Patient demographics including age, sex and levels of lesion are summarized in Table 1.

Table 1: Patient demographics PL

\begin{tabular}{|c|c|}
\hline Mean Age (Years) & $\mathbf{4 9 . 6 \pm 7 . 0 6}$ \\
\hline Total Number of Patients & 30 \\
\hline Male & $12(40 \%)$ \\
\hline Female & $18(60 \%)$ \\
\hline \multicolumn{2}{|c|}{ Level of Lesion } \\
\hline L4-L5 & $19(63.3 \%)$ \\
\hline L5-S1 & $11(36.7 \%)$ \\
\hline Grade of Slip (Meyerding Classification) \\
\hline Grade 1 & $12(40 \%)$ \\
\hline Grade 2 & $18(60 \%)$ \\
\hline
\end{tabular}

Table shows summary of mean age of patients, number of male and female patients, level of lesion, and Meyerding grade of slip.

\section{Surgical procedure}

PLF procedure have been performed using the standard described technique ${ }^{[12]}$. An open midline dissection was performed and was carried down the lamina bilaterally to the level of the facet joints and transverse processes. Segmental, bilateral polyaxial pedicle screw fixation was done at all levels treated, by free hand technique. Reduction screws are used selectively as per preoperative planning. Final screw position is confirmed using image intensifier. In cases with adjacent segment degenerative changes, fixation was extended to one more level. This was proceeded with laminectomy and decompression. Discectomy was done when required. Graft bed was prepared by decorticating transverse processes. Laminectomy bone chips and spinous process were used as bone graft and placed posterolaterally between the facets and transverse processes of the vertebrae (Figure 1).

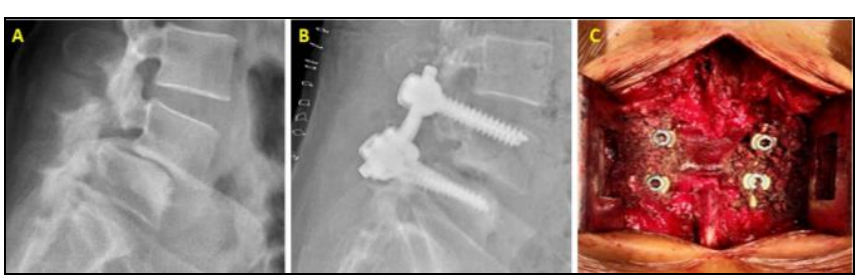

Fig 1: Posterolateral fusion

(A) Pre-operative lateral radiograph showing grade 2 spondylolisthesis of L4 over L5. (B). Post-operative lateral radiograph showing pedicle screw fixation. (C). Intra operative picture showing pedicles screws and bone graft placed posterolaterally.

\section{Outcomes measures}

Visual Analogue Scale (VAS) of low back pain, VAS of leg pain and Oswestry disability index (ODI) were assessed at regular intervals and comparisons were made between preoperative and 2 year follow up scores. Radiographic fusion was assessed by Lenke classification ${ }^{[13]}$.

\section{Statistical analysis}

Descriptive statistics were used. Data is analysed and plotted using the JASP (Version 0.10.2, University of Amsterdam) software. P value less than 0.05 is considered statistically significant. Numerical values are expressed as mean \pm standard deviation.

\section{Results}

Clinical and radiographic outcomes are summarized in Table 2.

The mean pre-operative VAS score low back ache was $7.87 \pm 0.68$ and at two years follow up was $1.37 \pm 0.85$. There is a significant improvement $(82.45 \%, P<0.001)$ in VAS scores for back ache (Figure 2A).

21 out of 30 patients had radiating pain along with back pain. The mean pre-operative VAS score for radiating pain was $3.83 \pm 2.72$ and at two year follow up was $0.3 \pm 0.47$. There is a significant improvement $(93.55 \%, P<0.001)$ in VAS scores for radiating pain (Figure $2 \mathrm{~B}$ ).

The mean pre-operative ODI score was $64.73 \pm 3.66$ and at two-year follow was $19.47 \pm 2.73$. There is a significant improvement $(69.86 \%, P<0.001)$ in ODI scores (Figure 2C).

Fusion was assessed following Lenke Classification. Based on the classification, 6 patients were Grade A, 15 patients were Grade B. Both Grades A and B are considered for Fusion. 7 patients were Grade $C$ and 2 patients were Grade D (Figure 3 A, B, C, D). Overall, there is $70 \%$ fusion rate radiologically. Overall outcome was assessed based on ODI score at 2 year follow up (Figure 2D). There was excellent outcome in 19 patients $(63.33 \%)$ and good outcome in remaining 11 patients $(36.67 \%)$.

There was no incidence of infections in either of the groups. Intraoperatively, 2 patients had dural tears, which were repaired immediately. None of the patients had any neurological deficits post-surgery. Re-operative rate at two years follow up was zero.

Table 2: Clinical and Radiographic Outcomes

\begin{tabular}{|c|c|c|}
\hline \multicolumn{3}{|c|}{ Visual Analog Scale- Low Back Ache $(\mathrm{N}=30)$} \\
\hline Pre-Operative & \multicolumn{2}{|l|}{$7.87 \pm 0.68$} \\
\hline 2 Year Follow Up & \multicolumn{2}{|l|}{$1.37 \pm 0.85$} \\
\hline Percentage Improvement & \multicolumn{2}{|l|}{$82.45 \pm 11.06$} \\
\hline Significance & \multicolumn{2}{|l|}{$P<0.001$} \\
\hline \multicolumn{3}{|c|}{ Visual Analog Scale-Radiating Pain $(\mathrm{N}=21)$} \\
\hline Pre-Operative & \multicolumn{2}{|l|}{$3.83 \pm 2.72$} \\
\hline 2 Year Follow Up & \multicolumn{2}{|l|}{$0.3 \pm 0.47$} \\
\hline Percentage Improvement & \multicolumn{2}{|l|}{$93.55 \pm 8.73$} \\
\hline Significance & \multicolumn{2}{|l|}{$P<0.001$} \\
\hline \multicolumn{3}{|c|}{ Oswestry Disability Index Score (N=30) } \\
\hline Pre-Operative & \multicolumn{2}{|l|}{$64.73 \pm 3.66$} \\
\hline 2 Year Follow Up & \multicolumn{2}{|l|}{$19.47 \pm 2.73$} \\
\hline Percentage Improvement & \multicolumn{2}{|l|}{$69.86 \pm 4.38$} \\
\hline Significance & \multicolumn{2}{|l|}{$P<0.001$} \\
\hline \multicolumn{3}{|c|}{$\begin{array}{l}\text { Fusion: Lenke Classification } \\
\end{array}$} \\
\hline Grade A* & 6 & \multirow{2}{*}{$70 \%$} \\
\hline Grade B* & 15 & \\
\hline Grade C & \multicolumn{2}{|l|}{7} \\
\hline Grade D & \multicolumn{2}{|l|}{2} \\
\hline \multicolumn{3}{|c|}{$\begin{array}{r}\text { Overall Outcome } \\
\end{array}$} \\
\hline Excellent (ODI 0-20) & \multicolumn{2}{|l|}{$19(63.33 \%)$} \\
\hline Good (ODI 21-40) & \multicolumn{2}{|l|}{$11(36.67 \%)$} \\
\hline
\end{tabular}

Table shows summary of VAS scores, ODI scores, Fusion rates and overall outcome in PLF. 


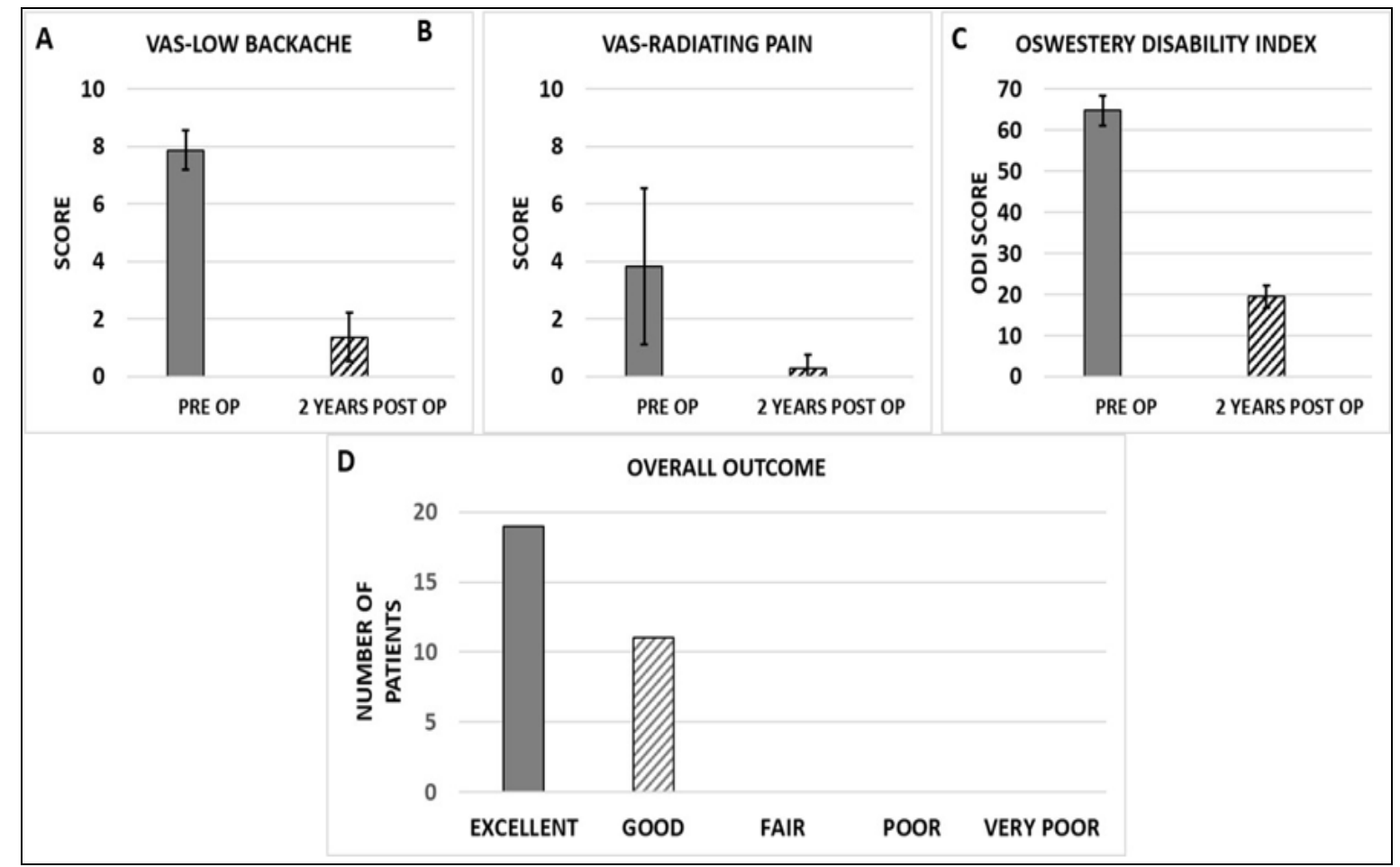

Fig 2: Functional Outcomes in PLF Comparison of VAS scores for low back ache (A), radiating pain (B), Oswestry Disability index score (C) of patients before surgery and at 2 years follow up. (D). Overall outcome of patients at 2 years follow up.
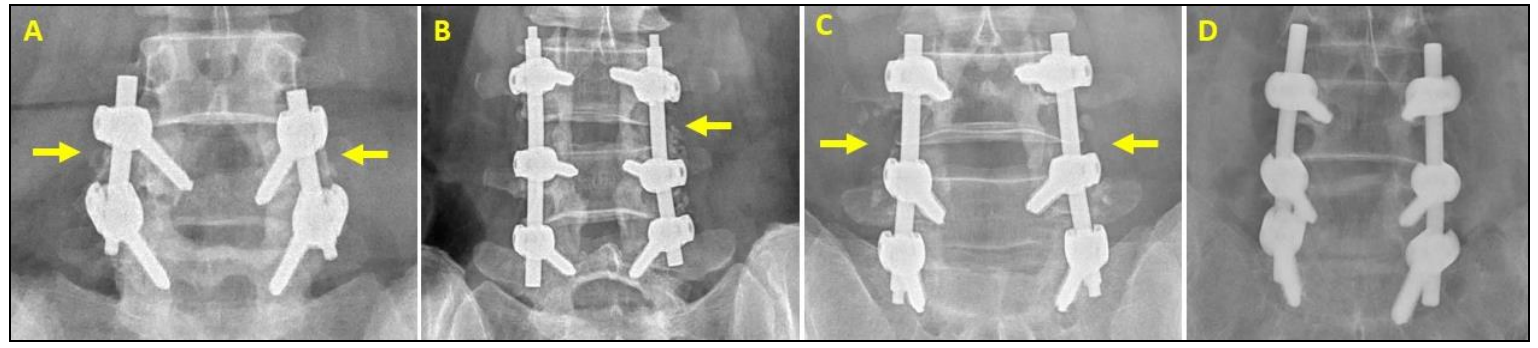

Fig 3: Fusion in PLF Radiographs showing Lenke's Grade A, B, C, D fusion in patients who underwent PLF

\section{Discussion}

Spondylolisthesis is one of the common causes for low back pain. The symptoms usually vary with severity of slip and associated degenerative changes. We included symptomatic patients with low grade (1 and 2, Meyerding Classification) lumbar spondylolisthesis in our study. All these patients were given a trial of conservative non-surgical treatment, but their symptoms have not been resolved. We chose posterior instrumentation with posterolateral fusion as out surgical procedure of choice. The goal of the surgical treatment included: the stabilization of the motion segment, the decompression of neural elements, the restoration of sagittal plane translation and prevent further slip.

The mean age of the patients being treated for spondylolisthesis, according to the available studies has varied from 39.5 years to 57.4 years, with range being 21 years to 70 years ${ }^{[14]}$. Our study included 30 patients with mean age being 49.6 years, with youngest patient being 38 years and oldest being 66 years.

Spondylolisthesis, especially degenerative has shown more prevalence in females, with studies ${ }^{[15]}$ showing a female: male $(\mathrm{F}: \mathrm{M})$ ratio of $1.3: 1$. We had 18 female and 14 male patients in our study, showing an F: M ratio of 1.5:1.

Lumbar spondylolisthesis commonly involves L4-L5 and L5S1 levels. L4-15 level is commonly involved in degenerative spondylolisthesis ${ }^{[16]}$, whereas isthmic spondylolisthesis is more common at L5-S1 level ${ }^{[17]}$. We included all the patients with spondylolisthesis from age 18 to 70 years. Our study had 19 patients $(63.3 \%)$ with lesion at L4-L5 level and 11 patients at L5-S1 level (36.7\%).

Endler et al., $2017^{[18]}$, in a prospective study reported that the VAS scores for back pain reduced by $63 \%$ and for radiating pain reduced by $55 \%$ in patients who underwent PLF at two years follow up. Challier et al., $2017^{[19]}$, in a randomized controlled trial (RCT) reported that VAS back pain improved by 3.8 and VAS leg pain improved by 3.4 in the PLF group. Etemadifar et al., $2016^{[20]}$ in a RCT with two years follow up reported that the VAS scores for back pain and leg pain were significantly decreased in PLF group. Lee et al., $2014^{[21]}$, in a prospective randomized study reported mean VAS scores for back pain decreased from 8.7 to 1.5 and for leg pain decreased from 6.4 to 0.9 at 2 years follow up. In our study, we also observed that at 2 years followed up, VAS score for back pain improved by $82.45 \%$ and that of radiating pain improved by $93.55 \%$.

We used ODI to assess functional outcome. We assessed percentage improvement in ODI at two years follow up. Endler et al, ${ }^{[18]}$, in their prospective study reported a $51.25 \%$ improvement in ODI score in PLF group. Challier et al, ${ }^{[19]}$ in their RCT, reported that ODI scores improved by 19 in the PLF group. Etemadifar et al., ${ }^{[20]}$ in their RCT, observed that ODI improved by $53.2 \%$ in the PLF group. Lee et al.'s study [21] showed a significant improvement of $70 \%$ in ODI scores at 2 year follow up in PLF group. In our study, we observed 
$69.86 \%$ improvement in ODI score. Based on ODI score $63.33 \%$ patients reported excellent outcomes.

We had a significant improvement in clinical outcome and we analyzed if the radiological outcome in terms of fusion supported it. Challier et al.'s RCT ${ }^{[19]}$ reported a fusion rate of $56.7 \%$ in the PLF group. Lee et al.'s study [21] showed a fusion rate of $89.7 \%$ at 2 year follow up in PLF group Levin et al., $2018^{[22]}$, in their meta-analysis of 2 RCT's and 5 cohort studies, reported that the pooled fusion success rate was $84.7 \%$ in the PLF group of patients. Müslüman et al., 2011 ${ }^{[23]}$, in a randomized study reported $84 \%$ fusion rate at 2 years follow up in patients who underwent PLF. In our study, we observed $70 \%$ fusion rate in PLF, which is consistent with the recent studies.

Every study has limitations and so did we. Our sample size is 30 , which is relatively small when compared to many prospective studies. Our duration of follow up is 2 years and longer studies may show higher fusion rates. Apart from this our operative technique and analysis of results are consistent with the recent and standard literature.

By analyzing our results and comparing them with recent studies, we conclude that posterolateral fusion with posterior instrumentation is a well-established and proven procedure to achieve better clinical outcomes and a solid fusion in adults with low grade spondylolisthesis.

\section{Declaration}

The authors did not receive any funding for this study. There are no conflicts of interests.

\section{References}

1. Haun DW, Kettner NW. Spondylolysis and spondylolisthesis: A narrative review of etiology, diagnosis, and conservative management. J Chiropr Med. 2005; (4):206-17.

2. Möller H, Hedlund R. Surgery versus conservative management in adult isthmic spondylolisthesis-a prospective randomized study: Part 1. Spine. 2000; 25(13):1711-1715.

3. Al Barbarawi MM, Audat ZM, Allouh MZ. Analytical comparison study of the clinical and radiological outcome of spine fixation using posterolateral, posterior lumbar interbody and transforaminal lumber interbody spinal fixation techniques to treat lumber spine degenerative disc disease. Scoliosis. 2015; 10:17.

4. Bridwell KH, Sedgwick TA, O’Brien MF, Lenke LG, Baldus $\mathrm{C}$. The role of fusion and instrumentation in the treatment of degenerative spondylolisthesis with spinal stenosis. J Spinal Disord. 1993; 6(6):461-72.

5. Abdu WA, Lurie JD, Spratt KF et al. Degenerative spondylolisthesis: does fusion method influence outcome? Four-year results of the spine patient outcomes research trial. Spine (Phila Pa 1976). 2009; 34(21):2351-60.

6. Gad Abdelkader S, El Zahlawy HN, Elkhateeb TM. Interbody fusion versus posterolateral fusion in treatment of low grade lytic spondylolisthesis. Acta Orthop Belg. 2019; 85(3):269-273.

7. Kelly JP, Alcala-Marquez C, Dawson JM, Mehbod AA, Pinto MR. Treatment of degenerative spondylolisthesis by instrumented posterolateral versus instrumented posterolateral with transforaminal lumbar interbody single-level fusion. J Spine Surg. 2019; 5(3):351-357.

8. Spiker WR1, Goz V, Brodke DS. Lumbar Interbody Fusions for Degenerative Spondylolisthesis: Review of Techniques, Indications, and Outcomes. Global Spine J
2019; 9(1):77-84.

9. Boktor J, Ninan T, Pockett R, Collins I, Sultan A, Koptan W. Lumbar fusion for lytic spondylolisthesis: Is an interbody cage necessary? J Craniovertebr Junction Spine. 2018; 9(2):101-106.

10. Endler P, Ekman P, Ljungqvist H, Brismar TB, Gerdhem $\mathrm{P}$, Möller H. Long-term outcome after spinal fusion for isthmic spondylolisthesis in adults. Spine J. 2019; 19(3):501-508.

11. Barbanti Bròdano G, Lolli F, Martikos K, Gasbarrini A, Bandiera S, Greggi $\mathrm{T}$ et al. Fueling the debate: Are outcomes better after posterior lumbar interbody fusion (PLIF) or after posterolateral fusion (PLF) in adult patients with low-grade adult isthmic spondylolisthesis? Evid Based Spine Care J. 2010; 1(1):29-34.

12. Keith D Williams. Spondylolisthesis. In: Frederick M Azar, James H Beaty, Terry Canale S. editors. Campbell's Operative Orthopaedics. 13th ed. Canada: Elsevier, Inc., 2017, 1741-1744.

13. Aygün H, Cakar A, Hüseyinoğlu N, Hüseyinoğlu U, Celik R. Clinical and radiological comparison of posterolateral fusion and posterior interbody fusion techniques for multilevel lumbar spinal stabilization in manual workers. Asian Spine J. 2014; 8(5):571-80.

14. Liu X, Wang Y, Qiu G, Weng X, Yu B. A systematic review with meta-analysis of posterior interbody fusion versus posterolateral fusion in lumbar spondylolisthesis. Eur Spine J. 2014; 23:43-56.

15. Wang YXJ, Káplár Z, Deng M, Leung JCS. Lumbar degenerative spondylolisthesis epidemiology: A systematic review with a focus on gender-specific and age-specific prevalence. J Orthop Translat. 2016; 11:3952. Published 2016 Dec 1. doi:10.1016/j.jot.2016.11.001.

16. Fitzgerald J, Newman PH. Degenerative spondylolisthesis. J Bone Joint Surg. Br. 1976; 58:184-192.

17. Wiltse LL, Winter RB. Terminology and measurement of spondylolisthesis. J Bone Joint Surg. Am. 1983; 65:768772.

18. Endler P1, Ekman P, Möller H, Gerdhem P. Outcomes of Posterolateral Fusion with and without Instrumentation and of Interbody Fusion for Isthmic Spondylolisthesis: A Prospective Study. J Bone Joint Surg. Am. 2017; 99(9):743-752.

19. Challier V, Boissiere L, Obeid I, Vital JM, Castelain JE, Bénard A et al. One-Level Lumbar Degenerative Spondylolisthesis and Posterior Approach: Is Transforaminal Lateral Interbody Fusion Mandatory?: A Randomized Controlled Trial With 2-Year Follow-Up. Spine. 2017; 42:531-9.

20. Etemadifar MR, Hadi A, Masouleh MF. Posterolateral instrumented fusion with and without transforaminal lumbar interbody fusion for the treatment of adult isthmic spondylolisthesis: A randomized clinical trial with 2-year follow-up. J Craniovertebral Junction Spine 2016; 7:43-9.

21. Lee GW, Lee SM, Ahn MW, Kim HJ, Yeom JS. Comparison of Posterolateral Lumbar Fusion and Posterior Lumbar Interbody Fusion for Patients Younger Than 60 Years with Isthmic Spondylolisthesis. Spine. 2014; 39(24):E1475-E1480.

22. Levin JM, Tanenbaum JE, Steinmetz MP, Mroz TE, Overley SC. Posterolateral fusion (PLF) versus transforaminal lumbar interbody fusion (TLIF) for spondylolisthesis: A systematic review and meta-analysis. The Spine Journal. 2018; 18(6):1088-1098. Doi: 10.1016/j.spinee.2018.01.028. 